\title{
Research on the Teaching Model of Reading Literary Classics from the Cross-cultural Perspective*
}

\author{
Yan $\mathrm{Wu}$ \\ College of Humanities and Social Sciences, Heilongjiang Bayi Agricultural University, Daqing, China
}

\begin{abstract}
College language courses in China should focus on the combination of carrying forward the excellent Chinese traditional culture and learning from foreign cultural achievements to guide students to see some aspect of the world in a world-wide sight. This paper advocates setting the curriculum which combines the introduction of the Western literary canons and the Chinese literary classics together. The purpose of this teaching model is to enhance the college students' humanistic qualities with the new teaching philosophy, new curriculum, teaching content, and teaching methods.
\end{abstract}

Index Terms - cross-culture, literary classics, teaching model, the other

\section{INTRODUCTION}

Whether it is "经典" in Chinese or "classic" in English, the term "classic" has the meaning of "outstanding, exemplary and authoritative" in both languages. In the article Literary Canons and Cultural Legitimacy -Literary Classics in the Field of Cultural Studies, Dong-feng Tao (2004) mentioned that "classic" had the meaning as standard, model, law and rule of paradigms. In his definition, the word "classic" has the meaning of "role model" for people to learn and to imitate it. It embodies the norms of cultural values and has the cultural power to shape people's thought and to restrain their behavior. Classics not only refer to the time-tested authoritative texts which have been passed down in history in the form of words or other symbols, but also contain the meaning of cultural norms hidden in the texts including the restriction of human beings' thinking, emotions and behavior.

Under the background of popular culture in the current consumption era, Chinese and western literary classics have gradually faded out of the view of people and have been neglected by contemporary college students in China. In the multicultural context, people who are in the predicament of real culture need to re-understand the meanings of literary classics, to re-read literary classics, and to re-experience the energy that classics bring to human beings.

Education plays an important role in the course of human growth. University education takes on the dual responsibilities of value rationality and value guidance. And either Chinese or western literary classics have their own unique cultures and traditions, which manifest their respective cultural values of geographical image in the aspects of language, social concept, literature, art, etc,. Therefore regarding the literary classics as the teaching content is one of the ways to achieve the aim of the university humanities education.

\section{The SignificANCE OF READING LITERARy ClASSICS}

Literary works need to be examined by time and history, and then to become classics. They are the accumulation of culture, the unrepeatable creations and rich in human nature. Literary classics reflect the collective memory of the nation and the capacity of the human spirit, and also provide a platform for people to communicate with each other while inheriting the traditional cultures.

Li-qun Qian (2007) believes that literary classics are the source of national spirit. He said that each country had its own classics, which could be said to be a household name, penetrating into the heart of every citizen. In his article, he mentioned that in terms of literary classics, they were the base of education, rooted in the minds of teenagers, and became the spirit of the young generations. Si-han Liu (2014) talked about that his aesthetic judgment was promoted after reading the literary classics. Since then, his aesthetic standard has been set up. And with this benchmark, he could realize the true meaning of literary classic. These two examples show that the literary classics are that wherever you are, they are the "compass" with which you find your spiritual home.

\section{A. Cultivating a Sound Personality with Profound Humanistic Values of Literary Classics}

Literature is the most dynamic and splendid part of human beings' culture. Throughout the long history, literary classics have embodied the underlying spirits of the world culture, reflected the people's pursuit for esthetics and faith

" This study is funded by the projects "Research on the Recessive Education on the Core Values of Socialism in College English Teaching", project No. GBE1317023 and "the Communication of Traditional Chinese Culture and the Cultivation of Core Values of Socialism", project No. sjd18210 
for ideal society, and moreover, demonstrated the diversified character of human beings. For instance, The Analects is the representative work of Confucianism in China, which reflects the profound influence of the mind, outlook on life, thinking mode, value orientation and ethics. Even in the contemporary society, Confucian thoughts still have their strong practical significance in China. Comments on Ci Poetry contains the meaning of human beings in the interpretation of $\mathrm{Ci}$, which shows the three states of doing research. The criticisms on imperial examination system, social corruption and feudal moral hypocrisy in The Scholars still have the warnings in today's society. The struggle between nature and ego in the Qld Man and the Sea, as well as the never-say-die spirit, inspires people to stick to the direction of life and to realize their self-worth. The pursuit of truth in Faust, the thought of suffering and tribulation, and the profound insights into human nature and humanistic spirits have practical guiding significance for the contemporary impetuous college students. Hamlet has contradictory and decisive life choices for justice, responsibility, kinship and love, which deserve our consideration and exploration.

The author has discussed with the students about reading literary classics and found that there were few students who had read through the Chinese Four Great Classical Novels. Compared with the popular and easy to understand novels, such as Journey to the West, Outlaws of the Marsh and Romance of the Three Kingdoms, the number of people reading A Dream of the Red Mansions was very small. The vast majority of students learned about the Chinese Four Great Classical Novels through films and TV series. For various reasons, films and TV series would be deleted or rewritten to the original works more or less. Therefore, they cannot faithfully reflect the author's thought. And for foreign literary classics, not only is the number of people reading less, but many students are unfamiliar with their names and even have never heard of them. The fact shows that many students prefer watching science fiction movies to reading literary classics.

Confusion, hesitation and helplessness existing in every phase of life make people lose the direction of life in the complicated world. People can find the calm and wise from literary classics. The thoughts and values conveyed in the literary classics will unconsciously influence the readers' thought, cultivate their temperament, purify their souls and arouse their strong sense of mission and responsibility.

\section{B. Improving the Literary Accomplishment with Richness and Canonization of Literary Classics}

Since the 1990s, consumerism has become one of the ideologies in Chinese society. In the era of big data and Internet, the popularization of computers and smart phones, as well as the extensive usage of microblog and WeChat, has changed the reading habits of college students. We have entered the era of "e-book", "shallow reading" and "picture reading". Bestsellers and e-books account for the main market of college students to read, thus their quantity and quality of reading present downward trend. Due to the change of social context, there is a disconnection between literary classics and the demands of the times, which leads to the crisis and marginalization of literary classics. And the prevalence of mass consumption culture has led to the deconstruction and decanonization of literary classics. The meaning and the artistic value of the literature classics have been washed out, and their authorities have been overturned. Literary classics are constantly confronted with "playful interpretation" and "rewritten" whose aesthetic values and the depth of the thought have been reduced by this consumption era to satisfy people's sense of stimulation and entertainment.

Literary classics are the must-read books for the promotion of literary accomplishment. Literary classics are the paradigms of literature in terms of language usage and layout. By reading literary classics in literature, culture and humanism, students' knowledge can be broadened. By this way, students obtain a certain literary theories, a sense of literature, creative ability and the ability to apply the texts to develop good reading habits and to have a higher level of literary appreciation. In the process of reading and interpreting the literary classics, we can understand their profound meaning, the beauty of language and artistic conception. Students' abilities to language application and writing can be improved. And there are many other benefits of reading literary classics, such as, to build a reasonable knowledge structure, to improve the knowledge level, to strengthen the study of humanities and cultural knowledge, to improve the oral and written expression abilities, to cultivate the strict logical thinking ability, and to promote students' literary accomplishments in all aspects.

In this era of information explosion, people have less room for reverie and spend less time thinking, but encounter more and more difficulties in thinking. However, one of the reasons for this phenomenon is not less in reading, but less in literary classics. The number of people reading literary classics is decreasing. One of the reasons is that the influence of literary classics on people cannot be realized in a short period of time in this utilitarian society. But the subtle influence of literary classics is the most valuable long-term investment in life. Literary classics are the essence of a country and a nation in the aspects of thoughts and culture, and the crystallization formed by time and national culture. The creation of literature is influenced by knowledge and moral standards of its time, and embodies the social ideology of the time, so different social groups in different times can revisit their values and reinterpret them by rereading. Reading literary classics not only increases knowledge and molds character, but also helps people rebuild their ideals and beliefs. People can establish and adhere to basic moral principles and value norms through reading and studying literary classics.

Each culture has its own characteristic values. So people from different cultural backgrounds have different perceptions of the same information. Because of the differences between cultures, they can absorb and learn from each other, and find themselves in the reading process. 


\section{The Meaning of Reading from the Perspective of Cross-culture}

Reading is a complex dialogue between the author, the reader and the text. In the process of cross-cultural reading, "misreading" will arise, whether it is "misreading" or "realizing", it is a creative action for interpreting the literature classics.

In Cultural Differences and Cultural Misreading, Dai-yun Le (2004) mentioned that taking foreign culture as a means to help you find yourself. Only from the outside, from an unfamiliar perspective of another culture, one could learn things that couldn't understand by themselves from the inside. She said that in the process of observation and interpretation of culture, everyone was inevitably restrained by their own cultural ideologies. Some problems within the "tradition" tend to be unexpected and invisible, only from the outside or from the perspective of foreign cultures can there be new discoveries and understandings. That means only by comparing with others and examining ourselves from the perspective of others can we completely understand our own native culture. These are the advantages of cross-cultural reading.

Cross-cultural reading is a bidirectional and conversational interpretation process. It enables us to see the potential significance and values of texts that are difficult to find from a single angle. In this process, heterogeneous culture and maternal culture are equal subjects, and they are equal dialogues with each other. Cross-cultural reading is based on the recognition of the differences between cultures. That is to say, there are no right or wrong answers to questions in cross-cultural reading, and readers can have different opinions. Because there are differences between cultures, we can have different perspectives to examine the heterogeneous cultures and that of ourselves. The common topics such as people's perception of life and life experience, which are intercommunity between cultures, as well as the literature on people's emotional and spiritual care which is the most easily to communicate and understand, make cross-cultural reading have the possibility of implementation.

\section{The Construction of Cross-cultural Teaching Model of Literary Classics}

Cross-cultural teaching model of the literary classics advocates the investigative study to guide the contemporary college students to read literary classics, and cultivates their sound personalities to improve the students' humanistic quality in language courses.

\section{A. Content Based on Chinese and English Literary Classics}

The greatness of literature lies in telling the story and evoking people's strong senses of mission and responsibility. The Chinese and English literary classics reflect the histories and cultures of the east and west for thousands of years. The thoughts conveyed by the works will gradually influence the readers' thinking to edify readers' disposition and purify their souls.

As compulsory courses, college Chinese and college English should balance the proportion of Chinese and English literary classics in teaching content. In college Chinese teaching, it is necessary to strengthen the reading depth of Chinese literary classics, and to increase the proportion of the classical chapters of western literature. In addition to mastering the basic knowledge of literature, students also need to know some literary theories. In the analysis and interpretation of Chinese literary classics, it is possible to make a new interpretation of them by using foreign literary theories from the cross-cultural perspective. College English should be appropriate to add the interpretation and appreciation of literary classics in teaching content which can make more students read the European and American literary classics and experience the differences between eastern and western literature, to change the phenomenon of "focusing on skills training, neglecting humanistic quality" in college English teaching. Through the study of compulsory courses, students have some basic understanding of American and European literary classics, which lays a foundation for the future improvement of their literature accomplishments. The optional courses enrich the reading categories of literary classics, covering the fields of poetry, prose, novels and other genres.

In the process of reading Chinese and western literary classics, students can improve their appreciation abilities of traditional literature and arts in the east and west. The rich forms and features of Chinese and western literary classics, the artistic styles of the different ages, geographical and ethnic characteristics can be learned. And students can also experience different local cultures and folk customs between the east and west. Reading the literary classics from the cross-cultural perspective not only spreads the human spiritual culture and inherits Chinese traditional culture with specific attachments, but also provides a new teaching model and way of thinking for the courses of college Chinese and college English. It is beneficial to the planning and development of literature courses and humanistic quality courses.

\section{B. Establishment of the Curriculum on the Basis of Compulsory and Optional Courses}

In the curriculum setting of our university, language courses of Chinese and English were relatively independent, and there was a lack of exchange and reference between the two courses. The college Chinese was the central part of the literary teaching, which only for liberal arts majors. It mainly taught Chinese and western literature, but it was confined by limited periods and the beneficial area was narrow. College English focused on the cultivation of language skills and the learning of western cultural knowledge. Due to the central position of language knowledge in the course of learning, cultural teaching was marginalized and neglected in college English teaching. And English has always been regarded as 
the language to be learned in order to cope with all kinds of examinations in China. Many students are tired of learning English, and regard it as time-consuming subject. In fact, this kind of teaching model is not consistent with the goal of cultivating intercultural communication competence and comprehensive cultural quality in college English curriculum. It is not beneficial to cultivate the comprehensive quality of college students.

The teaching model of reading literary classics from cross-cultural perspective is based on the combination of compulsory courses for college Chinese, college English, and the optional courses in reading literary classics. At our university, the teaching scope of college Chinese was narrow and the proportion of literature appreciation in college English teaching was low. In order to solve these problems, the optional courses become the best way to make up for a lack of literary classics teaching. Five optional courses, such as, the Chinese Literature and Life, Tang Poetry and Song $\mathrm{Ci}$, Selected Readings in Chinese Modern Literature, Selected Readings in Euro-American Literature, Masterpieces in Chinese and Foreign Literature have been setting up. At the same time, these courses are supplemented by various extracurricular activities themed on literary classics, such as recitation competition of literary classics, lectures on Chinese and foreign literary classics, etc., to create a rich cultural atmosphere on campus. It is the aim of the whole teaching to improve the students' humanistic quality by using the characteristics of canonical, profound and humanistic literary classics.

\section{Creation of Research-based Learning Classes with a Variety of Teaching Methods}

After the establishment of the new teaching model, teachers have changed their teaching concepts and insisted on the combination of language teaching and culture teaching in the compulsory courses. In particular, it is necessary to take advantage of the wide range of college English course to make a comprehensive appreciation of literary works by teaching forms and methods of vocabulary, reading, listening and writing. For optional courses, we have adopted flexible instructional modes. For instance, besides that a teacher teaches a course, it can also be the cooperation between College Chinese teachers and College English teachers cooperate with each other to teach the literary classics by stages. Or the teachers cooperate to interpret the literary classics on the same subject with different cultural backgrounds.

In learner-centered teaching activities, in order to arouse the learning potential of learners, teachers should make full use of various modern teaching methods to interpret literary classics from cross-cultural perspective. A variety of teaching methods have been adopted to create research-based learning classes. In teaching, teachers and students interpreted the literary classics "from linguistic analysis to aesthetic interpretation and to its sociological significance, and then rising to the significance of intellectual history." (En-ming Tian,2012) In this process, teachers encouraged students to think independently, to discuss the connotation of literary classics, and to conduct critical training, so that researching classroom became one of the ways to cultivate students' innovative thinking. In this way, the traditional teaching form of "what one says goes" and "one-way inculcation" can be changed, and students form their own views on literary classics. Rich teaching contents and different angles of interpretation to promote students "want to learn the classics", "love to learn the classics", and truly "enter into" the world of literature classics, to acquire the practical abilities in both English and Chinese languages and to comprehensively improve their literature accomplishments.

\section{Matters NeEding Attention in Teaching}

On the one hand, the teaching model of literary classics from cross-cultural perspective can break the traditional independent practice of university language courses to change the bottleneck of English teaching .And on the other hand, we can further strengthen our understanding and love of our national culture through the integration of Chinese and western literary classics. In teaching, teachers could cultivate students to read literary classics from a cross-cultural perspective in the following aspects.

\section{A. Cultivation of Cross-cultural Awareness}

Chinese culture is a typical historical and high-context culture, focusing on the accumulation of experience, with "nature and humanity", perception of intuitive thinking, humanistic pragmatism, etc.. And the western cultures rooted in the ancient Greek is the philosophical and low-context culture, which attaches great importance to the perception of the world, analysis as the main method, is characterized by rational metaphysical speculation. So some people think that it is unlikely to achieve real communication and understanding because of their different sources, different ways of thinking and different cultural frameworks. But in literature, there is a complementary relationship between the east and west. This kind of complementary is in contrast with "the other" to understand and highlight oneself characteristics more clearly. The purpose of cross-cultural reading is to realize the mutual absorption and complement of the eastern and western literature, but it is not to turn the other into the same or become the other. Cross-cultural reading mainly uses the way of thinking or literary theories in a culture to interpret the text of another culture, thus obtaining a new interpretation and understanding of the text.

The teaching model emphasizes the re-understanding and interpretation of Chinese and western literary classics from a cross-cultural perspective. Cross-cultural reading is a two-way, conversational interpretation process that enables us to see the potential significance and values of many texts that are difficult to find within a single culture. Reading literary classics from cross-cultural perspective puts us in a double bind. On the one hand, reading literary classics is a dialogue between history and reality. In the context of history and reality, rereading the classics makes a modern interpretation of 
them. On the other hand, any culture is a result of mutual communication, and the "pure", "original" culture is just wishful thinking. Rereading the classics in the cultural field of Chinese and western culture is to discover the new connotation of literary classics, to obtain spiritual satisfaction and spiritual care, and to reconstruct the values and moral values. The aim of reading literary classics from cross-cultural perspective is intended to release the potential meaning of the enclosed texts in the modern context.

In teaching process, teachers guide students to analyze the texts, explain the cultural phenomenon, and explore the content of the unfamiliar culture, to constantly reflect on the learning process and to sum up learning experience. Cross-cultural teaching has a very wide range of content. "To teach fishing is better than to fish", it is better to cultivate the students' cross-cultural awareness and sensitivity, to make them have the independent learning methods and establish the idea of lifelong learning.

\section{B. Setting up a Cultural Relativistic View}

The process of interpretation of literary classics from cross-cultural perspective is the process of constantly reflecting on the native culture and comparing with other cultures. The learners who have the open and flexible thinking mode are required to have the point of view of cultural relativity theory, and to eliminate or weaken ethnocentrism to understand their values and behavior habits objectively.

In the process of cross-cultural reading, teachers should guide students to realize that heterogeneous culture and native culture are equal. Cross-cultural reading is based on the recognition of the differences between cultures. In the process of cross-cultural reading, there are no right or wrong answers, but different opinions.

Through comparing and imitating their respective characteristics of Chinese and western cultures, teachers combine the Chinese and western literary classics as the teaching content, which can enhance the students' rational knowledge of human cultures, to assist students to understand the rich connotation and unique humanities values implied in literary classics and the deep spiritual pursuit of the Chinese nation. They can have a more comprehensive and objective understanding of contemporary China and the outside world, to avoid the formation of extreme thoughts and cultural prejudice.

\section{The Necessity of "Rereading" the Literary Classics}

In the context of multiculturalism, people who are in the predicament of real cultures need to re-understand the classics and their meanings, to reread classics and re-experience the energy that classics bring to human beings.

The classics are something constantly being reread. Italian scholar Italo Calvino (1999) said in his book Why Reading the Classics, "The classics are those books which you usually hear people saying: 'I'm rereading...', never 'I'm reading...' A classic is a book which with each rereading offers as much of a sense of discovery as the first reading. A classic is a book which even when we read if for the first time gives the sense of rereading something we have before." In the process of continuously rereading literary classics, their unique, unexpected, and original characteristics can be found. We put the prefix "re-"in front of the verb "read" to emphasize "read repeatedly", just as the Chinese saying "A book is read a hundred times and its meaning is seen." For literary classics, every reading has its own comprehension, and in each time it is different. The more you read it, the more you understand it. Literary classics can be constantly reread, showing that they have the characteristics of different interpretations by different people in different times. The content or thoughts of the classics are beyond their times which leave the deep impression to us or hidden deeply in people's mind in the unconscious state, making readers of any cultures in every era having their own understanding.

\section{CONCLUSION}

Using literary classics as the medium, combining College English and Chinese language classes together can achieve communication between the Chinese and western literature, to help learners to understand their contribution to and influence on the development of human society. This teaching model not only embodies the humanistic quality education values, but also makes Chinese culture friendlier, more attractive and British and American culture more concrete, more vivid and easier to grasp. Its teaching goals are to improve students' autonomous learning of Chinese excellent traditional culture and exploring ability, to train students' consciousness of cultural innovation, to strengthen students' sense of responsibility and mission to carry forward Chinese excellent traditional culture.

\section{REFERENCES}

[1] Bing-hui Song. (2008). Literary Canon in the Cross-cultural Context. Journal of Lanzhou University (Social Sciences) 5,59-64

[2] Dai-yun Le. (2004). Comparative Literature and Comparative Culture. Shanghai: Fudan University Press.

[3] Dong-feng Tao. (2004). Literary Canons and Cultural Legitimacy-Literary classics in the field of cultural studies, Comparative Literature in China 3,58-74.

[4] En-ming Tian. (2012). The Communication Significance of University Literature Education in the Field of Humanistic Science. Continue Education Research 9,105-107.

[5] Hong-ling Zhang. (2007). Intercultural Approach to Foreign Language Teaching. Shanghai: Shanghai Foreign Language Teaching Press.

[6] Italo Calvino. (1999). Translated by Martin Mclaughlin. Why We Read the Classics. England London: Penguin Group 3-5.

[7] Li-na Wei \& Yi-min Zhang. (2011). The Succession and Transition of Literary Canons and Their Cross -Cultural Perspective. 
Foreign Literature Studies 1, 173-175.

[8] Li-qun Qian. (2007). How to Treat Confucius to Xun Lu's Tradition. Luxun Research Monthly 9, 4-11.

[9] Si-han Liu. (2014). Read Classics if the Time is Limited. Shenzhen Commercial Daily 10, 21.

Yan Wu was born in Songyuan, Jilin Province, China in 1980. She received her Master's degree in linguistics from Harbin Normal University in 2011. Her research interests include applied linguistics and foreign language teaching. 